\title{
APLIKASI MEDIA PEMBELAJARAN INTERAKTIF SENI BANUA BANJAR
}

\author{
Kholik Setiawan'), \\ Teknik Informatika, Fakultas Teknologi Informasi, Universitas Islam Kalimantan \\ Jl. Adhiyaksa No. 2, Kayu Tangi, Sungai Miai, Banjarmasin Utara, \\ Kota Banjarmasin, Kalimantan Selatan 70123 \\ Telp (0511) 3304352 \\ Email : kholiksetiawanfti@gmail.com ${ }^{1)}$
}

\begin{abstract}
ABSTRAK
Media Interaktif dan Game dapat dimanfaatkan oleh masyarakat dan kaum pendidik sebagai media untuk menyampaikan berbagai jenis pendidikan dan pembelajaran tentang budaya yang menarik dan menyenangkan atau juga untuk anak-anak sebagai pengenalan dan permainan yang menarik. Manfaat lain adalah aspek kecerdasan dan reflek saraf yang sebenarnya juga sedikit banyak terasah dalam sebuah animasi interaktif dan game, terutama animasi yang bersifat kompetitif. Dengan belajar melalui visualisasi yang menarik, diharapkan semangat untuk belajar tentang seni akan lebih termotivasi. Karena selalu dimainkan berulang ulang dan terus menerus sampai para pemain game merasa puas, maka dengan sendirinya materi-materi yang disampaikan akan mudah dicerna dan dimengerti oleh pemain game. Media interaktif yang digunakan untuk pembelajaran seni daerah banua banjar yang meliputi seni sastra, tari, musik, teater dan seni rupa dan di terapkan berbasis android agar dapat dengan mudah di gunakan dan di akses oleh pengguna. Construct 2 adalah software pembuat game atau aplikasi berbasis HTML5 yang dikhususkan untuk platform 2D. Software ini dikembangkan oleh Scirra.
\end{abstract}

Kata kunci : MPI, Seni, Construct 2, Android

\section{PENDAHULUAN}

Perkembangan MPI (media pembelajaran interaktif) yang pesat dikarenakan dukungannya terhadap pembelajaran yang bisa diakses setiap saat dan disegala tempat. Dalam MPI, pengelolaan informasi yang secara dinamis, yaitu mampu menyimpan atau memunculkan informasi, seperti menyimpan nilai atau score, memunculkan saran atau solusi, atau informasi lain nya merupakan hal mendasar terkait perkembangan MPI yang merupakan bagian dari materi dan game juga memerlukan basis data dalam mengolah kontennya.

Indonesia merupakan negara kepulauan dengan kondisi geografisnya yang luas dan beragam. Hal tersebut menjadikan Indonesia juga memiliki kebudayaan yang sangat beragam terutama banua banjar. Keberagaman budaya tersebut dapat terlihat secara fisik melalui seni-seni, musik-musik maupun bahasa . Banua Banjar memiliki sastra, tari, teater, musik dan seni rupa, masing-masing ciri khas tersebut akan di tampilkan kembali dalam media pembelajaran interaktif seni MPI.

Generasi muda sebagai generasi penerus bangsa adalah penerus tradisi budaya Indonesia juga. Namun, pengaruh budaya asing yang semakin gencar, membuat generasi muda tidak tertarik untuk mempelajari budaya tradisional, bahkan sedikit demi sedikit telah menjauhi dan mulai melupakan budaya tradisional bangsa. Pengetahuan seni banua banjar hanya sebatas pada acara-acara tertentu saja, misalnya acara pernikahan, acara adat tradisional, dan sebagainya. Bahkan hal ini tidak saja terjadi di daerah perkotaan, tetapi juga di daerah pedesaan yang biasanya lebih kuat. Maka itu dikenalkan materi tentang seni khusus banua banjar beserta gamenya agar lebih menarik

Media Interaktif dan Game dapat dimanfaatkan oleh masyarakat dan kaum pendidik sebagai media untuk menyampaikan berbagai jenis pendidikan dan pembelajaran tentang budaya yang menarik dan menyenangkan atau juga untuk anak-anak sebagai 
pengenalan dan permainan yang menarik. Manfaat lain adalah aspek kecerdasan dan reflek saraf yang sebenarnya juga sedikit banyak terasah dalam sebuah animasi interaktif dan game, terutama animasi yang bersifat kompetitif. Dengan belajar melalui visualisasi yang menarik, diharapkan semangat untuk belajar tentang seni akan lebih termotivasi. Karena selalu dimainkan berulang ulang dan terus menerus sampai para pemain game merasa puas, maka dengan sendirinya materi-materi yang disampaikan akan mudah dicerna dan dimengerti oleh pemain game.

- Manfaat Media Pembelajaran Interaktif ini diharapkan akan memotivasi siswa untuk belajar mandiri, kreatif, efektif dan efisien. Selain itu dengan Media Pembelajaran Interaktif ini, diharapkan dapat mengurangi kejenuhan karena selama ini proses pembelajaran yang dilakukan oleh kebanyakan sekolah adalah metode tatap muka

\section{LANDASAN TEORI}

\subsection{Media Pembelajaran}

Media dalam pembelajaran memiliki fungsi sebagai alat bantu untuk memperjelas pesan yang disampaikan guru. Media juga berfungsi untuk pembelajaran individual dimana kedudukan media sepenuhnya melayani kebutuhan belajar siswa. Menurut Edgar Dale Dalam Sigit Prasetyo (2007: 6) "Secara umum media memiliki kegunaan yaitu: memperjelas pesan agar tidak terlalu verbalistis, mengatasi keterbatasan ruang, waktu tenaga dan daya indra, menimbulkan gairah belajar, interaksi lebih langsung antara murid dengan sumber belajar, memungkinkan anak belajar mandiri sesuai dengan bakat dan kemampuan visual, auditori \& kinestetiknya.

\subsection{Multimedia Pembelajaran Interaktif}

Pengertian multimedia menurut Agus Suheri (2006: 3) adalah media yang menggabungkan dua unsur atau lebih media yang terdiri dari teks grafis, gambar, foto, audio, video dan animasi secara terintegrasi. Multimedia terbagi menjadi dua kategori, yaitu: multimedia linier dan multimedia interaktif.

Multimedia interaktif adalah suatu multimedia yang dilengkapi dengan alat pengontrol yang dapat dioperasikan oleh pengguna, sehingga pengguna dapat memilih apa yang dikehendaki untuk proses selanjutnya. Contoh : multimedia interaktif adalah: multimedia pembelajaran interaktif, aplikasi game, dll.

\subsection{Animasi}

Animasi menurut Agus Suheri (2006: 2) "Merupakan kumpulan gambar yang diolah sedemikian rupa sehingga menghasilkan gerakan". Animasi mewujudkan ilusi (illusion) bagi pergerakkan dengan memaparkan atau menampilkan satu urutan gambar yang berubah demi sedikit (progressively) pada kecepatan yang tinggi. Animasi digunakan untuk memberi gambaran pergerakan bagi sesuatu objek. Animasi membolehkan sesuatu objek yang tetap atau statik dapat bergerak dan kelihatan seolah-olah hidup. Animasi multimedia merupakan proses pembentukan gerak dari berbagai media atau objek yang divariasikan dengan efek-efek dan filter, gerakan transisi, suara-suara yang selaras dengan gerakan animasi tersebut. Animasi di dalam sebuah aplikasi multimedia dapat menjanjikan suatu visual yang lebih dinamik serta menarik kepada penonton karena animasi memungkinkan sesuatu yang mustahil atau kompleks berlaku di dalam kehidupan sebenarnya direalisasikan di dalam aplikasi tersebut. Efektifitas animasi dalam pembelajaran tidak hanya berhubunan dengan bagaimana animasi itu diterima dan dikonsepkan, namun juga bagaimana animasi tersebut dirancang.

Ada tiga jenis format animasi menurut Dina Utami (2007: 1), yaitu:

1) Animasi Tanpa Sistem Kontrol.

Animasi ini hanya memberikan gambaran kejadian sebenarnya (behavioural realism), tanpa ada control sistem. Misal untuk pause, memperlambat kecepatan pergantian frame, Zoom in, Zoom Out dll.

2) Animasi Dengan Sistem Kontrol.

Animasi ini dilengkapi dengan tombol kontrol. Misal tombol untuk pause, zoom in, zoom out, dll.

3) Animasi Manipulasi Langsung.

Animasi manipulasi langsung menyediakan fasilitas untuk pengguna berinteraksi langsung dengan kontrol navigasi (misal tombol dan slider). Pengguna bebas untuk menentukan arah perhatian. Menekan tombol atau menggeser slider akan menyebabkan 
perubahan keadaan. Hasilnya dapat langsung dilihat dan kejadiannya dapat diulang-ulang.

Animasi pada saat ini banyak dimanfaatkan untuk berbagai kebutuhan dalam berbagai kegiatan mulai dari kegiatan santai sampai serius, maupun sebagai fungsi utama sampai fungsi tambahan atau hiasan. Animasi dibangun berdasarkan manfaatnya sebagai perantara atau media yang digunakan untuk berbagai kebutuhan di antaranya sebagai media presentasi. Pada media presentasi, animasi digunakan untuk membuat menarik perhatian para penonton atau peserta presentasi terhadap materi yang disampaikan oleh presenter. Dengan penambahan animasi pada media presentasi membawa suasana presentasi menjadi tidak kaku. Dengan penambahan animasi diharapkan dapat tercapai penyampaian informasi atau terjadinya komunikasi yang baik dalam kegiatan presentasi.

\subsection{Construct 2}

Construct 2 adalah tools yang digunakan dalam membuat sebuah game tanpa memerlukan pengetahuan tentang pemrograman. caranya hanya melakukan drag and drop item yang tersedia, menambahkan perilaku mereka, dan membuat mereka menjadi bergerak dengan sebuah event.

Construct 2 memiliki interface yang sangat mirip dengan produk microsoft office. hal ini membuat mudah bagi orang-orang yang terbiasa dengan produk office. karena sifat HTML 5 masih eksperimental, ada beberapa fitur dalam pembuatan game yang mungkin tidak bekerja dengan baik di semua perangkat. Construct 2 merupakan tools yang dapat dipelajari dengan cepat, dalam pembuatan game dapat dilakukan dengan mengekspor permainan sendiri dan bekerja dalam mobile device

\section{ANALISIS PERANCANGAN SISTEM}

\subsection{Konsep Media}

a. Media Interaktif

Konsep dari Animasi interaktif adalah pembelajaran, pembelajaran seni banua banjar yang meliputi dari sastra, tari, musik, teater, dan seni rupa yang semuanya berasal dari banua banjar.

b. Evaluasi Materi

Konsep evaluasi ini terdapat beberapa soal dan secara acak tentang seni banua banjar berdasarkan materi dari media interaktif dan pemain akan diminta menjawab soal dari evaluasi tersebut.

\subsection{Konsep Game}

Konsep game ini yaitu menjawab dan menyelesaikan pertanyaan yang berbentuk gambar, game sederhana terdiri dalam beberapa pertanyaan pada setiap levelnya.

a. Level 1, pemain diminta menjawab pertanyaan dengan tampilan gambar yang terdiri 5 pertanyaan gambar.

b. Level 2, pemain diminta menjawab pertanyaan dengan tampilan gambar yang terdiri 7 pertanyaan gambar.

c. Level 3, pemain diminta menjawab pertanyaan dengan tampilan gambar yang terdiri 7 pertanyaan gambar.

\subsection{Struktur Menu}

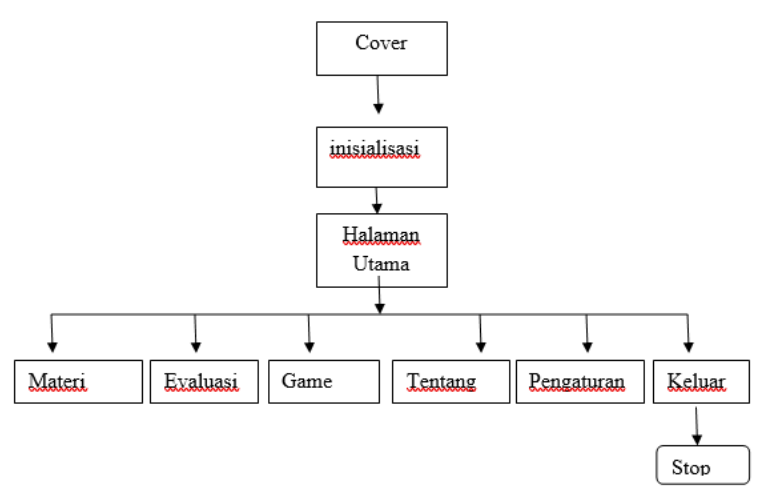

Gambar 1 Struktur Menu MPI

Berikut adalah keterangan dalam alur MPI (ELearning dan Game)

- Materi: Materi dalam pembelajaran ini ada 5 yaitu sastra, tari, musick, teater dan seni rupa. Masing-masing akan menampilkan materi materinya.

- Evaluasi : Halaman untuk menjawab soal-soal latihan dari materi, pertanyaan yang diberikan berbatas waktu dan juga ada penilaian score.

- Games : Games pembelajaran ini yaitu game menebak gambar, dan menyusun puzzle gambar secara acak. User harus menyelesaikan game pada level 1 terdahulu untuk lanjut ke level berikutnya, dalam level 1 user harus menuntaskan menebak 5 pertanyaan berupa gambar, dan menyusun puzzle gambar. Setelah 
menuntaskan level 1 maka user akan melanjutkan ke level 2 yaitu menebak 7 pertanyaan gambar, dan menyusun gambar.

- Tentang : Halaman informasi penelitian

- Pengaturan : Halaman untuk mengatur musik animasi.

- Keluar : Untuk keluar dari aplikasi

\subsection{RANCANGAN STORYBOARD}

Storyboard merupakan gambaran skenario yang dibuat secara bertahap yakni setiap scene dalam animasi dan game. Storyboard ini yang nantinya akan menerangkan susunan dari materi animasi \& game yang dibuat.

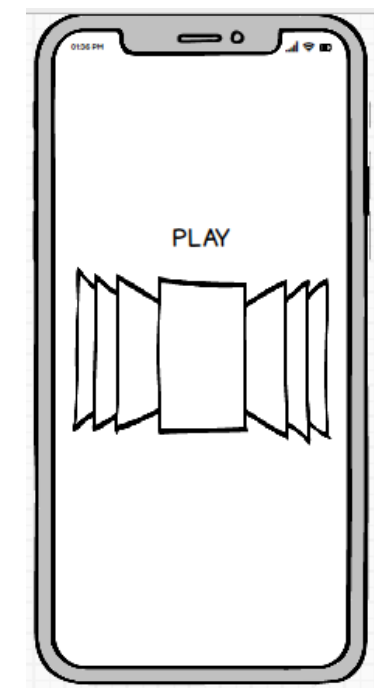

Gambar 2 Storyboard Cover

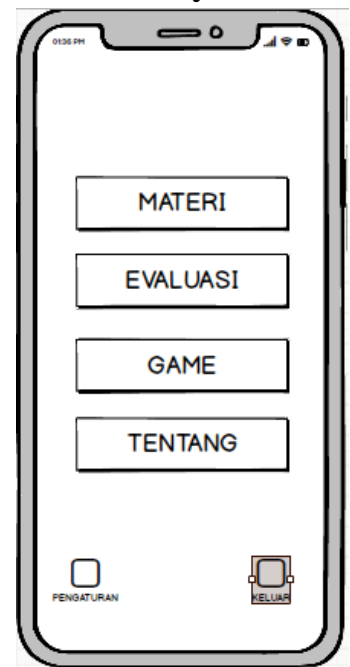

Gambar 3 Storyboard Menu Utama

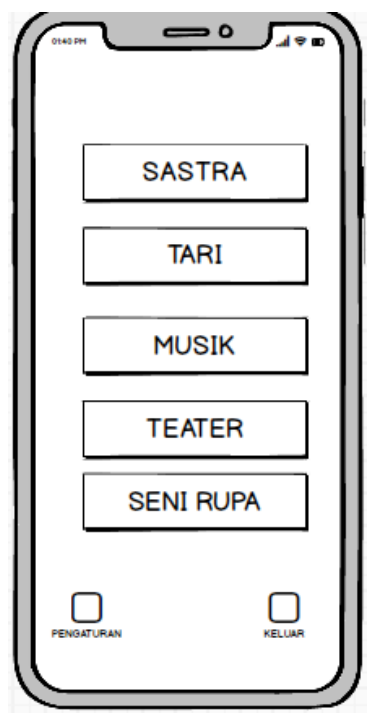

Gambar 4 Storyboard Menu Materi

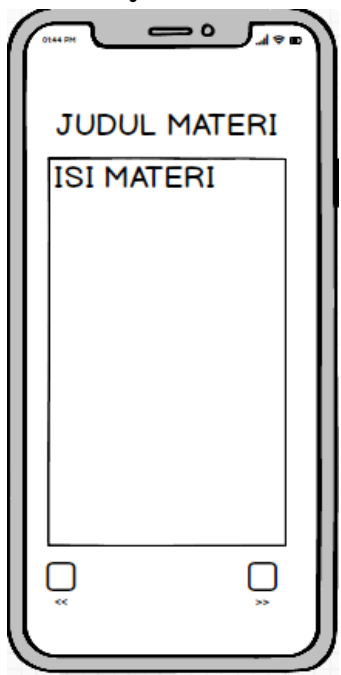

Gambar 5 Storyboard Isi Materi

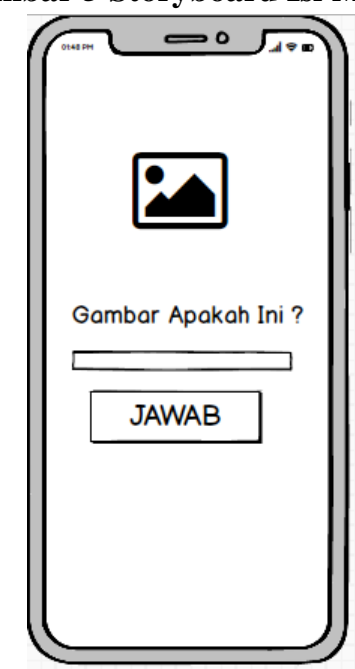

Gambar 6 Storyboard Game Tebak Gambar 


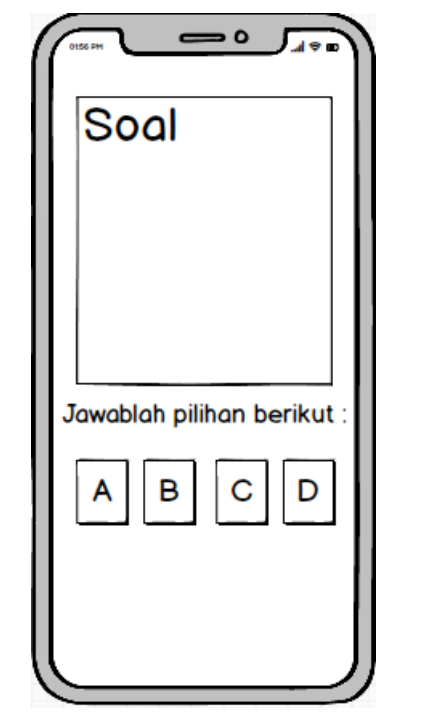

Gambar 7 Rancangan Evaluasi

\section{HASIL DAN PEMBAHASAN}

Penelitian ini menghasilkan suatu aplikasi Media Pembalajaran Interaktif Seni Banua Banjar game berbasis smartphone Android. Aplikasi terdiri dua bagian, bagian pertama merupakan materi dan bagian kedua. Materi di ambil dari materi seni banua banjar yang meliputi sastra, tari, musik, teater dan seni rupa.

a) Layout Cover

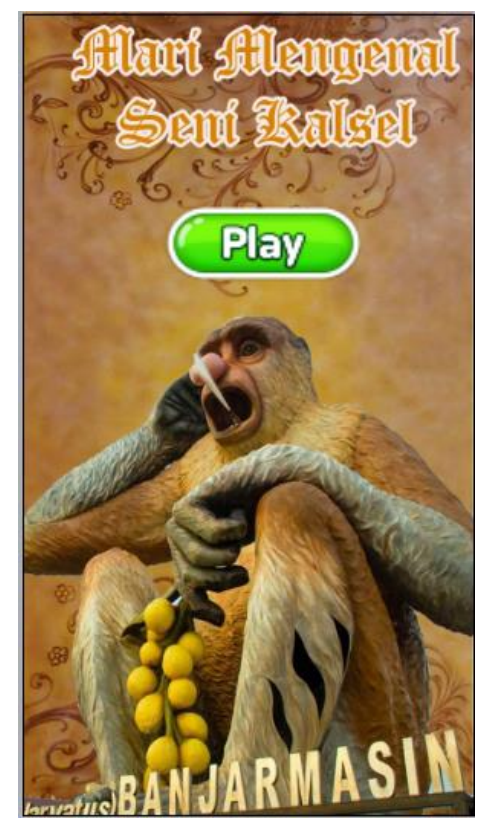

Gambar 8 Layout Cover

b) Layout Main Utama

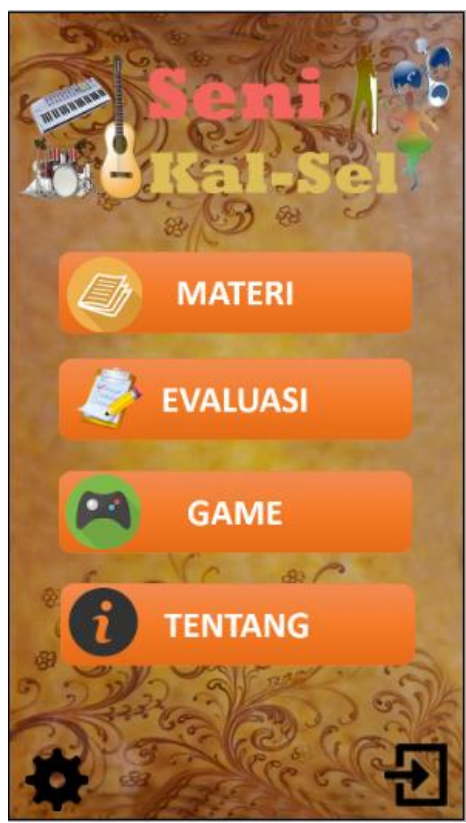

Gambar 9 Main Utama

c) Layout Main Materi

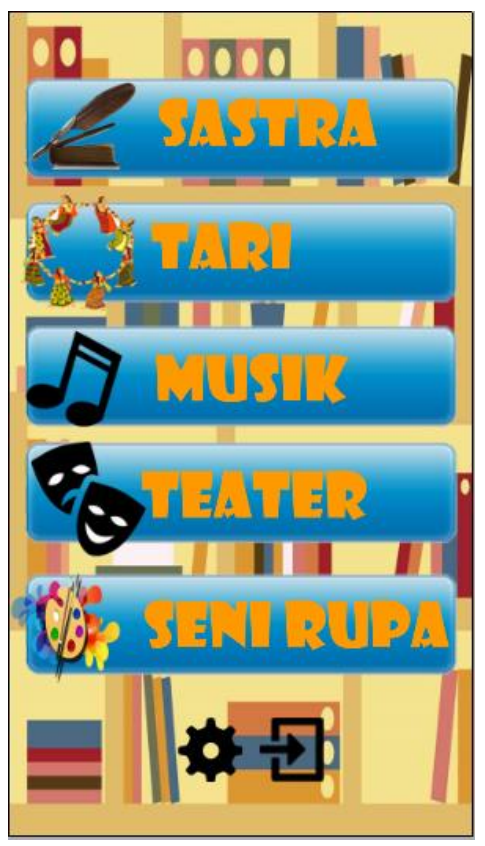

Gambar 10 Layout Main Materi

d) Layout Materi Sastra 


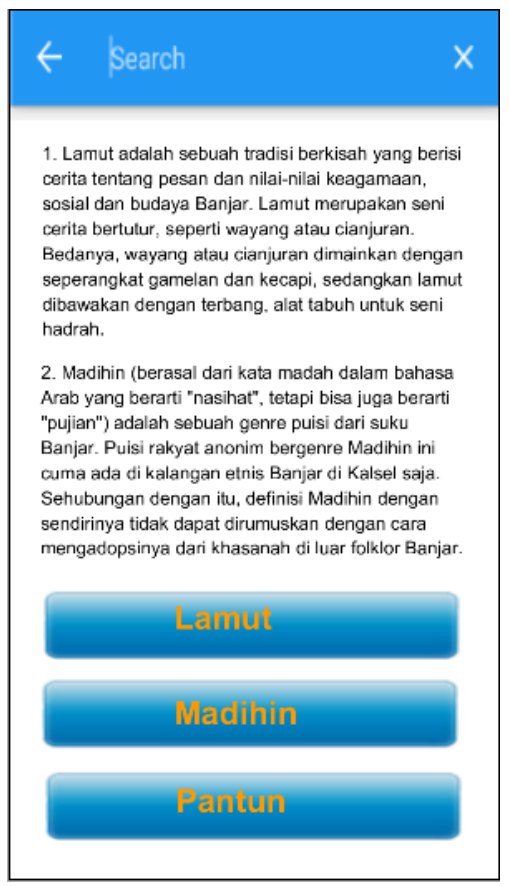

Gambar 11 Layout Materi Sastra

e) Layout Materi Tari

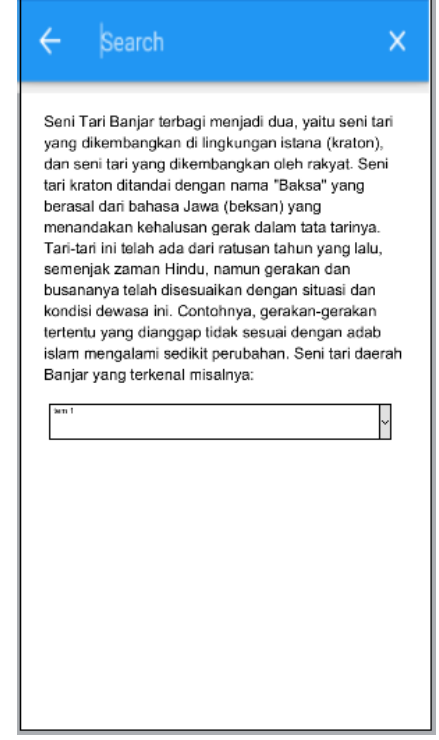

Gambar 12 Layout Materi Tari

f) Layout Materi Musik

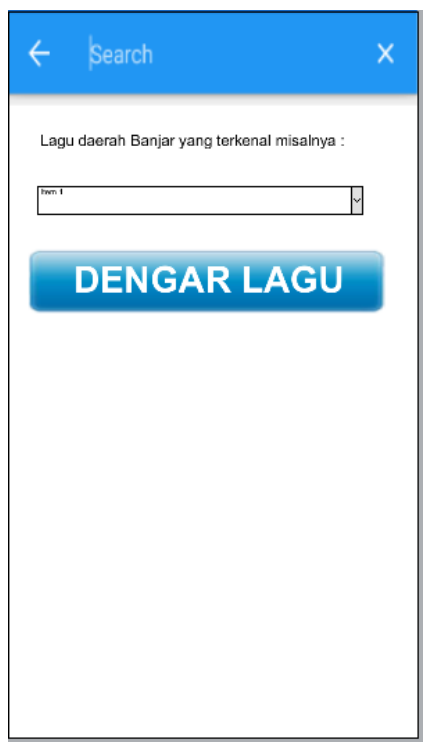

Gambar 13 Layout Materi Musik

g) Layout Materi Teater

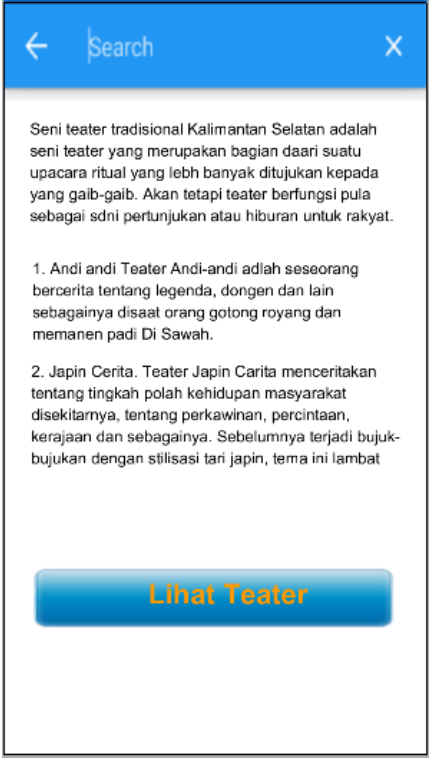

Gambar 14 Layout Materi Teater

h) Layout Materi Seni Rupa 


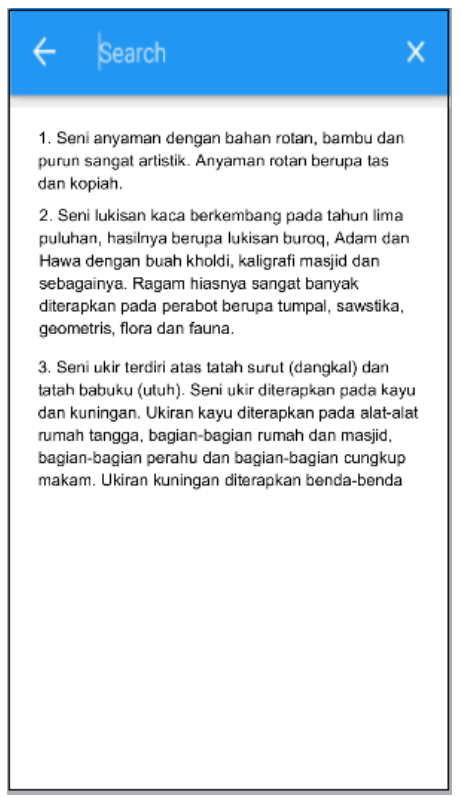

Gambar 15 Layout Materi Seni Rupa

i) Layout Evaluasi

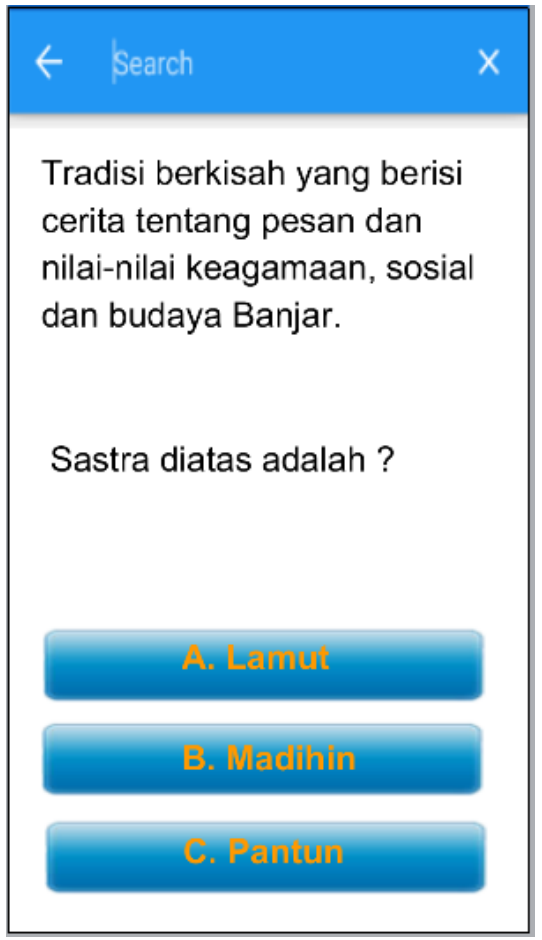

Gambar 16 Layout Evaluasi j) Layout Game

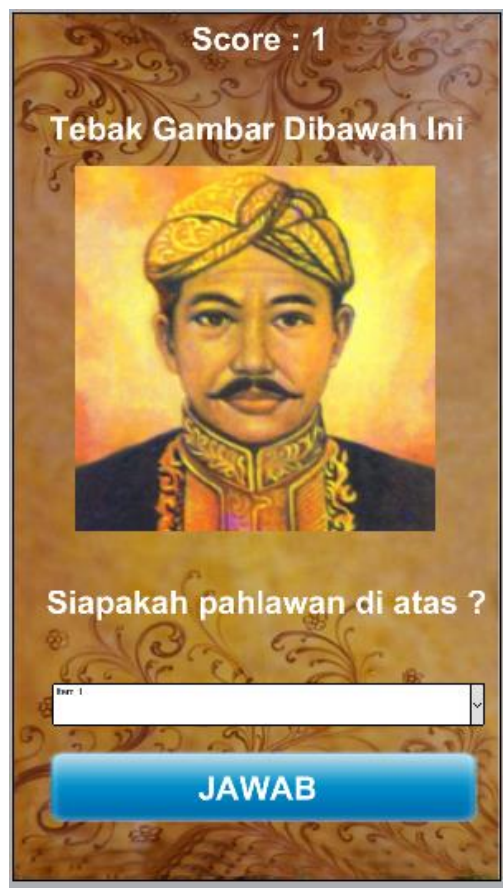

Gambar 17 Layout Game

\section{KESIMPULAN}

Setelah dilakukan pengujian dan analisa program, maka dapat diperoleh simpulan sebagai berikut :

a. Media Pembelajaran Interaktif dapat mempermudah pembelajaran

b. MPI yang dibuat dapat digunakan dimana saja dan siapa saja, karena sifat dari MPI ini untuk pembelajaran

c. MPI yang dibuat dapat diakses lebih dari satu pengguna dan siapa saja pada waktu bersamaan

d. MPI hanya materi seni dari banua banjar.

e. Game yang mudah digunakan dan menguji pengetahuan tentang materi pada MPI. 